\title{
Livre acesso à publicação acadêmica
}

\author{
Teodora Marly Gama das Neves \\ Mestre em ciência da informação - IBICT/UFRJ, 1992. \\ Analista em C e T - CIN/CNEN - RJ/Brasil. \\ E-mail: tmarly@cnen.gov.br
}

\section{Resumo}

Descreve a criação e o desenvolvimento de um catálogo de periódicos eletrônicos de livre acesso ao texto completo, mantido pelo Centro de Informações Nucleares, da Comissão Nacional de Energia Nuclear, como suporte das atividades de busca e localização de documentos, para o fornecimento de cópias.

\section{Palavras-chave}

Periódicos eletrônicos; Publicação eletrônica; Comunicação científica; Livre acesso; Texto completo.

\section{Open access to scholarly publishing}

\section{Abstract}

It is a description of a catalog of open electronic journals maintained by Centro de Informações Nucleares/Comissão Nacional de Energia Nuclear, as a support to its activities.

\section{Keywords}

Electronic journals; Electronic publishing; Scientific communication; Open access; Full text.

\section{INTRODUÇÃO}

O advento do fenômeno chamado Internet veio provocar verdadeira revolução no ordenamento das coisas no mundo da informação e do conhecimento. Barreiras foram derrubadas, distâncias encurtadas, paradigmas quebrados, atitudes, hábitos e comportamentos modificados. Se, por um lado, encontrou-se solução para uma variedade de pendências, por outro lado, muitos problemas emergiram.

Para fins deste artigo, cujo objetivo é relatar um dos trabalhos que está sendo desenvolvido pelo Centro de Informações Nucleares (CIN), da Comissão Nacional de Energia Nuclear (Cnen), é necessária breve contextualização do que vem ocorrendo no cenário da comunicação científica e, mais especificamente, na forma como o conhecimento acadêmico passou a ser disponibilizado. "Publicar em papel", "publicar eletronicamente", "como disponibilizar", "custos das assinaturas", entre outras, são questões que podem ser vistas sob diversos ângulos, de acordo com o papel e os interesses de cada ator: as editoras, com seus interesses comerciais, lutando por não perder o monopólio que vêm detendo ao longo do tempo; a comunidade científica, com sua necessidade de comunicação, buscando alternativas para manter-se visível entre seus pares; os organismos de informação, com seu papel social de mediar e de democratizar o conhecimento, envidando todos os esforços para manter a completeza e o acesso a coleções de periódicos científicos. São essas questões que se colocam em face de uma nova realidade: o mundo virtual da Internet.

Alternativas que atendam a seus interesses têm sido buscadas por editores e pela comunidade científica. As discussões que têm sido mantidas entre eles estão disponíveis na revista Nature (http://www.nature.com/ nature/debates/e-access/), e em 2003 foi aberto mais um fórum de discussões. Trata-se do boletim Open Access Now (http://www.biomedcentral.com/openaccess/archive/), publicado pela editora BioMed Central.

No Brasil, estará sendo realizado, no mês de abril de 2005, o 11으órum Permanente de Conhecimento e Tecnologia da Informação (http://www.corj.rei.unicamp.br), promovido pela Universidade de Campinas (Unicamp), cujo tema central (Open Source: o livre acesso à informação científica) tem por objetivo "apresentar à comunidade universitária alternativas para o acesso livre ao registro e divulgação da produção científica" (Fapesp, 2005). 
A comunidade científica percebeu uma possível solução para o problema que vem enfrentando nas possibilidades que a Internet oferece com seus mecanismos de publicação direta, solução essa que está implementando como um meio de aumentar sua visibilidade. "Pesquisadores passaram a criar arquivos eletrônicos de preprints e posprints como alternativa para publicação direta de seus trabalhos em texto completo, os assim chamados open archives." (Marcondes, 2002, 2003), que Sena (2000) assim descreve,

... mantido pelo Laboratório Nacional de Los Alamos, Novo México, iniciado em 1991 por Paul Ginsparg, que se tornou um repositório global de artigos não-revisados pelos pares, nas áreas da física, matemática, ciência da computação e ciências nãolineares. Esses arquivos começaram com o trabalho de uma comunidade de 200 físicos, crescendo, com o passar dos anos, para 35 mil usuários, localizados em mais de 70 países, processando mais de 70 mil transações eletrônicas por dia. Conseguiu, inclusive, suplantar alguns periódicos tradicionais em certas áreas da física como meio de disseminação de novas pesquisas e também para propósitos arquivísticos.

A possibilidade de publicar eletronicamente o periódico científico e a preocupação com o acesso a essa publicação resultaram em uma série de iniciativas em todo o mundo. A título de ilustração, cite-se, no Brasil, a criação do Portal SciElo - Scientific Electronic Library Online (http://www. scielo.br), que surgiu como resultado de um projeto de pesquisa da Fundação de Amparo à Pesquisa do Estado de São Paulo (Fapesp), em parceria com o Centro LatinoAmericano e do Caribe de Informação em Ciências da Saúde (Bireme), abrigando atualmente 128 títulos e cuja metodologia para publicar, garantir a preservação e prover livre acesso ao texto completo dos periódicos foi estendida posteriormente para outros países da América Latina, como Chile (http://www.scielo.cl/), México (http://scielomx.bvs.br/scielo.php), Cuba (http://scielo.sld.cu/scielo. php) e Venezuela (http://www.scielo.org.ve/scielo.php).

Outro tipo de iniciativa também relevante, porém no Canadá, está relacionada com o Public Knowledge Project - PKP - http://pkp.ubc.ca/, um empreendimento de pesquisa da University of British Columbia, que, entre outras possibilidades, disponibiliza gratuitamente o programa OJS - Open Journal Systems (http://www. pkp.ubc.ca/ojs/) para publicação e gestão de periódicos eletrônicos. Essa ferramenta já está disponível em português, tendo sido adaptada e lançada pelo Instituto Brasileiro de Informação em Ciência e Tecnologia (Ibict) sob a denominação de Sistema Eletrônico de Editoração de Revistas - Seer (http://www.ibict.br/ secao.php?cat=SEER)
Ainda que esse relato esteja focado na publicação periódica, é oportuno mencionar também a existência de outras iniciativas do IBICT na área acadêmica, como contribuição ao livre acesso às publicações: 1) o projeto Biblioteca Digital Brasileira - BDB, que estará integrando em um único portal diversos repositórios de informação digital do país; 2) participação no projeto Biblioteca Digital de Teses e Dissertações - BDTD (http://bdtd.ibict.br/ bdtd/), que tenciona integrar os sistemas de informação de teses e dissertações existentes nas instituições de ensino superior; 3) o Sistema de Publicações Eletrônicas de Teses e Dissertações - TEDE (http://tedesite.ibict.br), disponibilizado no âmbito da BDTD em duas ferramentas para download: TEDE Modular e TEDE Simplificado; 4) o sistema Arquivos Abertos da Sociedade Brasileira de Genética (http://www.sbg.ibict.br/), que surge para "dinamizar o processo de comunicação entre pesquisadores da área de ciência e tecnologia” (Garcia, 2003).

As iniciativas relacionadas com a publicação eletrônica de periódicos têm resultado na formação de um imenso e disperso acervo, livremente disponível na rede, que não pode ser ignorado, especialmente, pelos organismos de informação. Nesse ponto é onde se insere o Centro de Informações Nucleares (CIN), da Comissão Nacional de Energia Nuclear (Cnen), que há três décadas vem oferecendo à comunidade acadêmica um serviço de fornecimento de texto completo - o Servir (http:// cin.cnen.gov.br/servir/index2.html). Esse serviço está voltado prioritariamente para o usuário interno da Cnen, porém sua organização e infra-estrutura permitem atender também a solicitações oriundas de qualquer área do conhecimento, não apenas da nuclear, motivo que justifica sua população-alvo ser constituída de usuários internos e externos, do Brasil e do exterior.

Pela necessidade que o Servir tem de manter organizadas suas ferramentas de trabalho e ao perceber, no momento de localização da fonte, a quantidade de documentos livremente disponíveis na Internet, a equipe do CIN deu início, em 2001, de forma sistematizada, à coleta de títulos de periódicos eletrônicos de livre acesso, cujo desenvolvimento relata-se a seguir.

\section{O CATÁlOGO DE PERIÓDICOS ELETRÔNICOS DE LIVRE ACESSO AO TEXTO COMPLETO DO CIN}

Como dito anteriormente, há cerca de 30 anos o CIN vem mantendo um serviço de fornecimento de texto completo - Servir, em apoio aos serviços de atualização profissional - Sonar (http://cin.cnen.gov.br/sonar/ index $2 . h t m l)$ e de busca retrospectiva - Suprir, que disponibiliza. Em recente pesquisa de imagem, os serviços 
do CIN passaram por uma avaliação de sua clientela interna (http://cin.cnen.gov.br/pesquisas/index.htm), cujos resultados só o estimulam a continuar na busca de facilidades e melhoramentos informacionais e tecnológicos para a comunidade usuária.

Registre-se que, pela própria necessidade dos serviços que oferece, faz parte da 'tecnologia CIN' o desenvolvimento de bases de dados, pois nem sempre as informações de que necessita estão organizadas convenientemente, então se torna necessário construí-las (Sayão e Barros, 1995). Cite-se como exemplo a base de dados ANAIS - Catálogo Coletivo de Anais de Eventos (http://cin.cnen.gov.br/ catalogos/busca/), que foi criada com o objetivo de ser apenas um meio de localização interna, mas que hoje é mais uma ferramenta de busca disponível para uso de todas as bibliotecas cooperantes com o CIN.

Também foi por necessidade do serviço que a equipe técnica do CIN deu início à coleta de títulos de periódicos eletrônicos de livre acesso ao texto completo, disponíveis na Internet. Nascia assim, timidamente, o Perinter, nome provisório atribuído ao catálogo. De formato simples, sua planilha eletrônica (Excel) é constituída de quatro campos que abrigam: (1) título do periódico, (2) datas de início/fim da publicação eletrônica, (3) endereço (URL) e (4) observações. Este campo foi criado para notificar o usuário do catálogo sobre alguns aspectos relevantes do periódico. Nele estão explicitadas: (a) restrições de acesso ; (b) significado de siglas constantes do título do periódico; (c) formato digital do documento, quando menos comum; (d) títulos antecessores e sucessores; (e) lapsos de tempo sem publicação; (f) idiomas menos comuns em que o texto está publicado; (g) ISSN, quando necessário diferenciar o título; (h) instrução de acesso, quando necessário; (i) nova URL, quando o mesmo título está hospedado em lugares diferentes, a partir de datas diferentes.

\section{CRITÉRIO DE SELEÇÃO DOS TÍTULOS}

Tendo em vista o fim a que se destina o catálogo, a idéia é ser abrangente quanto às áreas do conhecimento, porém seletivo quanto à natureza da matéria veiculada. Braga e Oberhofer (1982), ao traçarem diretrizes para a avaliação de periódicos brasileiros, agruparam os periódicos em três categorias: científicos, técnicos e de divulgação. Na seleção dos títulos a serem incorporados, procura-se seguir essa categorização, eliminando qualquer publicação de estilo popular, ou seja, aquela cujo conteúdo veiculado não desperta interesse na comunidade acadêmica. Assim, pode-se dizer que o catálogo é composto por (a) revistas científicas (journals), (b) revistas de divulgação científica (magazines) e (c) boletins técnicos (bulletins/ newsletters).

\section{TIPOS DE ACESSO AO DOCUMENTO}

Ao longo dos três anos de existência do catálogo, percebeu-se que várias modificações ocorriam quanto à política de acesso ao texto. À medida que os títulos iam sendo coletados, observava-se não haver uniformidade na sua disponibilização. Os editores responsáveis adotam, cada um, políticas segundo seus interesses. Ora permitem, ora não permitem o acesso ao texto completo, o que vem a se tornar um complicador no gerenciamento do catálogo. Veja, a seguir, as variações observadas nos títulos coletados:

a) na maioria, o acesso a todos os números eletrônicos e a todos os artigos é completamente livre; aqui estão enquadrados os títulos da base SciElo (http://www.scielo. br), por exemplo;

b) para alguns títulos, o acesso requer registro e/ou assinatura individual sem custos, como no caso do THE SCIENTIST (http://www.the-scientist.com/archives/ archives_2001.htm);

c) no caso da editora IoP (Institute of Physics), todos os títulos estão disponíveis, porém somente por 30 dias a partir da data de publicação on-line, o NUCLEAR FUSION (http://www.iop.org/EJ/toc/0029-5515/44/9) é um exemplo; a inclusão de tais títulos neste catálogo tem sua razão de ser: eles contêm o que de mais recente saiu sobre aquele assunto;

d) alguns títulos que mantêm em paralelo assinatura da versão impressa só disponibilizam o livre acesso após determinado período, que pode ser de seis meses, um ano, dois anos etc. Aqui insere-se o ADVANCES IN PSYCHIATRIC TREATMENT (http://apt.rcpsych.org/ contents-by-date.0.shtml). Verificou-se que a incidência maior dessa modalidade de acesso ocorre na área médica. Em contrapartida, verificou-se, também, por observação, que é na área médica que está concentrado o maior volume de títulos totalmente livres;

e) há casos em que o acesso é parcial, sofre restrição para alguns artigos, veja-se, por exemplo, o AMERICAN SCIENTIST (http://www.amsci.org/amsci/search. html).

Na literatura foram encontradas nove modalidades de acesso (Willinsky, 2003). Entre elas inclui-se a permissão de livre acesso somente ao sumário do periódico e ao resumo do artigo, categoria essa em que se encontra a maioria dos periódicos científicos eletrônicos e que não faz parte do escopo do catálogo ora relatado. 


\section{METODOLOGIA DE COLETA}

A criação do catálogo se deu pela necessidade de organizar a informação que se vinha obtendo na Internet, pois, a cada novo pedido de cópia de artigo de periódico, recebido pelo Servir, processava-se uma busca para checar sua existência em formato eletrônico e aos poucos foi-se percebendo o quanto crescia o volume de títulos de livre acesso disponíveis. A partir de então, passou-se a sistematizar a coleta por meio do Google (http://www.google.com), uma das poderosas ferramentas de busca na Internet. Termos combinados e bem específicos como journal, free on-line, full text articles e open access foram os utilizados naquela fase inicial. $\mathrm{O}$ retorno apontava quase sempre para uma infinidade de fontes (links), algumas significativas catálogos já organizados (Free Medical Journals - http:// www.freemedicaljournals.com/), editoras (HighWire - http://highwire.stanford.edu/), diretórios (DOAJ - Directory of Open Access Journal - http://www. doaj.org/), etc. -, mas também apontava para muito "lixo". Felizmente a experiência já havia mostrado que, mesmo no Google, não vale a pena ir além da 10 ${ }^{\mathrm{a}}$ página de retorno. Em cada link selecionado, procurou-se verificar:

a) veracidade do livre acesso - algumas vezes essa informação estava explicitada no texto sobre o periódico, ainda assim, adotou-se por norma abrir sempre um artigo: 1) do primeiro volume/número disponível eletronicamente; 2) de alguns outros posteriores, de forma aleatória; 3 ) do último número publicado, obrigatoriamente;

b) disponibilidade de todos os artigos - quando um ou outro não estava disponível, uma nota passou a ser colocada na coluna de observação;

c) data de início da publicação eletrônica e, em alguns casos, data em que o periódico deixou de ser publicado;

d) formato digital do documento (HTML, PDF, DOC, PostScript) - a princípio foram ignorados os periódicos cujos artigos estavam em PostScript, dada a impossibilidade que se teria de baixar o documento. Posteriormente, com a aquisição do software Acrobat Distiller, que transforma tais arquivos em arquivos PDF, passou-se então a considerálos. Nesse caso, também acrescentou-se uma nota na coluna de observação, por tratar-se de formato de arquivo menos comum.

Feitas todas as verificações, o título era ou não acrescentado ao catálogo. Com o passar do tempo e com a experiência obtida pelo uso intenso da Internet, outras fontes de busca foram surgindo, como, por exemplo:
1) o Portal de Revistas Científicas em Ciências da Saúde da Bireme (http://portal.revistas.bvs.br/main. php?home $=$ trueelang $=\mathrm{pt}$ ), cuja pesquisa avançada contém a opção de busca "texto eletrônico, disponível e gratuito", retornando à relação de todos os títulos de livre acesso;

2) o portal SciElo - Scientific Electronic Library Online (http://www.scielo.br), em todas as suas versões (Brasil, Cuba etc.), que inclui unicamente títulos de livre acesso ao texto completo. No caso da Bireme, mesmo sabendose a priori serem os periódicos de livre acesso, a checagem por meio de download de algum artigo do primeiro e do último números publicados não deixou de ser feita. Em muitos casos, teve-se a surpresa de solicitação de senha de acesso;

3) a base de dados Latindex - Sistema Regional de Informação em Linha para Revistas Científicas da América Latina, Caribe, Espanha e Portugal (http://www.latindex. unam.mx/) e outras fontes mais. Na atualidade, a coleta se dá basicamente de três formas: pelo conhecimento de novas fontes (editoras, diretórios etc.), pela checagem do título do artigo e/ou do periódico solicitado ao Servir e por indicação de alguém da equipe.

\section{MANUTENÇÃO, DISPONIBILIDADE E REVISÃO DO CATÁLOGO}

Atualmente*, o catálogo reúne 2.097 títulos. Sua manutenção se dá de forma manual e ocasional, isto é, não-rotineira. Primeiro, porque não existe um tempo exclusivo dedicado a essa atividade e, além disso, não é com tanta freqüência que a equipe toma conhecimento de um novo título ou de uma nova fonte.

Hoje o catálogo está disponível para consulta em três ambientes: planilha Excel, Intranet e Internet. A planilha eletrônica continua sendo alimentada, por ser uma ferramenta que permite um controle do total de títulos existentes e que facilita algumas buscas de cunho administrativo. Cada novo título coletado é imediatamente incorporado nos três ambientes. No ambiente WEB, a consulta pode ser feita pela lista alfabética dos títulos disponíveis e também por qualquer palavra do título (http://extranet.cnen.gov.br/cin/perinter/) ${ }^{* *}$.

Desde sua criação em 2001, o catálogo já passou por uma revisão geral, levada a efeito em um período de

\footnotetext{
* Abril de 2005.

${ }^{* *}$ No momento em que este relato foi aceito para publicação (março/2005), o catálogo passou a ter nova denominação que se encontra disponível no endereço http://extranet.cnen.gov.br/cin/livre/, com alguns aprimoramentos introduzidos.
} 
sete meses ininterruptos (maio a novembro de 2003). A revisão consistiu em acessar cada título para verificar (a) a validade da URL informada, (b) a permanência do livre acesso e (c) a continuidade da publicação. Dessa revisão resultou a exclusão de 176 títulos, por três motivos: 1) não estarem mais disponíveis no endereço indicado (página não encontrada); 2) terem sido retirados da Web; 3) terem deixado de ser de livre acesso (solicitação de senha). No primeiro caso, foi possível, algumas vezes, a recuperação de alguns títulos, mediante busca feita no Google pelo nome completo do periódico, quando então passava-se a conhecer a nova URL.

\section{PRÓXIMOS PASSOS}

O volume de informação existente no catálogo já permite que aprimoramentos sejam introduzidos para tornar mais fácil e efetiva a recuperação da informação. Em operação conjunta a ser realizada pela equipe envolvida, o catálogo passará por algumas modificações em seu design, arranjo e modalidade de busca. Sua página na Web ganhará um novo formato. Uma breve descrição surgirá no momento em que o ponteiro do mouse passar por determinado ponto ao lado de cada título. Buscas simples e avançadas poderão ser realizadas. Informações sobre fontes de indexação, avaliação pelos pares e idioma do texto serão acrescentadas. Os títulos estarão disponíveis em uma única ordem alfabética e também sob as categorias em que vierem a ser classificados. Objetivando-se manter uniformidade com outras fontes nacionais, serão adotadas as categorias existentes na tabela de áreas do conhecimento utilizada pelo portal Capes (http://www.capes.gov.br/ Documentos/TabelaAreasConhecimento.PDF). Feitas essas modificações, a URL do catálogo será divulgada no meio acadêmico (rede de bibliotecas cooperantes, instituições mantenedoras de portais etc.), para inserirse no conjunto de fontes de busca já existentes.

\section{CONSIDERAÇÕES FINAIS}

Reunir títulos de periódicos eletrônicos que se encontram dispersos na Internet e disponibilizá-los para uso próprio e de outrem passou a ser um dos objetivos do CIN, como sistema de informação institucionalizado e inserido na problemática do livre acesso ao conhecimento científico. Dessa forma, acredita-se que o ganho passa a ser de todos, da comunidade acadêmica e dos serviços de informação, por constituir mais uma fonte de busca do texto completo.

O desenvolvimento e a manutenção desse catálogo têmse mostrado uma experiência instigante, por saber-se que em momento algum alcançará o estágio de produto final acabado. Lida-se com um acervo virtual sobre o qual não se tem controle, que pode a qualquer momento sofrer modificações sem que se tenha conhecimento imediato. Daí decorrer a necessidade de constante monitoramento/revisão para que se possa garantir um mínimo de confiabilidade na ferramenta que está sendo construída e oferecida.

Também necessário se faz a participação efetiva da comunidade técnica usuária (bibliotecas, centros de informação e outros) traduzida em feedback, tanto no que tange a possíveis imprecisões e modificações observadas quando do uso da ferramenta, quanto em sugestões de novos títulos passíveis de ser incorporados.

Ao longo de seus 34 anos de existência, o trabalho cooperativo tem sido a tônica adotada pelo CIN, em todos os seus empreendimentos. Somar esforços visando ao bem comum tem-se revelado receita ideal para obtenção de bons resultados.

Artigo recebido em 30-09-2004 e aceito para publicação em 29-03-2005.

\section{Agradecimentos}

Registro meus agradecimentos (1) à minha chefe imediata bibliotecária Odete Correa de Azevedo Coutinho, responsável pelo Servir, que com seus conhecimentos muito enriqueceu este relato, (2) ao analista de sistema da Cnen Eduardo Augusto Orosco Galvão, parceiro neste empreendimento e responsável pela parte técnica do desenvolvimento e manutenção do banco de dados, e (3) à amiga Icléia Thiesen Magalhães Costa, que generosamente imprimiu seu olhar crítico nos originais deste texto.

\section{REFERÊNCIAS}

BRAGA, Gilda Maria; OBERHOFER, Cecília Alves. Diretrizes para a avaliação de periódicos científicos e técnicos brasileiros. Rev. Lat. Doc., v. 2, n. 1, p. 27-31, enero/jun.1982.

FÓRUM PERMANENTE DE CONHECIMENTO E TECNOLOGIA DA INFORMAÇÃO, 11., 2005, São Paulo. São Paulo : FAPESP, 2005. Disponível em:

$<$ http://www.agencia.fapesp.br/boletim_dentro.php?data[id_materia_ boletim] $=3551>$. Acesso em: 08 abr. 2005.

GARCIA, Patrícia de Andrade Bueno. Provedores de dados de baixo custo: publicação digital ao alcance de todos. 2003. Dissertação (Mestrado em Informática) - Universidade Federal do Paraná, Curitiba, Curitiba, 2003. Disponível em:

<http://eprints.presidentekennedy.br:9000/archive/00000017/01/patricia_ dissertfinal.pdf>. Acesso em: 08 abr. 2005.

MARCONDES, Carlos Henrique; SAYAO, Luis Fernando. Documentos digitais e novas formas de cooperação entre sistemas de informação em CeT. Ciência da Informação, Brasília, v. 31, n. 3, p. 42-54, set./dez. 2002. 


\section{Livre acesso à publicação acadêmica}

et al. O estado da arte dos periódicos acadêmicos eletrônicos

brasileiros. In: ENANCIB, 2003. Anais... [S. 1. : s. n., 2003?]. 1 CD-ROM.

SAYÃO, Luis Fernando; BARROS, Anna Christina. T. M. de. Centro de informações nucleares: 25 anos de apoio da CNEN à área de CeT. Ciência da Infornação, Brasília, v. 24, n. 2, p. 232-240, maio/ago. 1995.

SENA, Nathália Kneipp. Open archives: caminho alternativo para a comunicação científica. Ciência da Informação, Brasília, v. 29, n. 3, p. 71-78, set./dez. 2000.
WHAT is the public knowledge project? Disponível em: <http://www. pkp.ubc.ca/about/what.html>. Acesso em: 24 ago. 2004.

WILLISNKY, J. The nine flavors of open access scholarly publishing. Postgraduate Journal of Medicine, v. 49, n. 3, p. 263-267, 2003. Disponível em: $\quad<$ http://www.jpgmonline.com/article.asp?issn=0022-3859; year $=$ $2003 ;$ volume $=49 ;$ issue $=3 ;$ spage $=263 ;$ epage $=267 ;$ aulast $=$ Willinsky $>$. Acesso em: 24 ago. 2004. 
